\title{
Improved cardiac arterial spin labelling in the mouse heart by optimisation of acquisition and analysis
}

\author{
Adrienne E Campbell ${ }^{1 *}$, Anthony N Price ${ }^{2}$, Jack A Wells ${ }^{1}$, Mark F Lythgoe ${ }^{1}$, Roger J Ordidge ${ }^{3}$ \\ From 2011 SCMR/Euro CMR Joint Scientific Sessions \\ Nice, France. 3-6 February 2011
}

\section{Objective}

In this study, a time-efficient segmented $\mathrm{k}$-space arterial spin labelling (ASL) sequence is implemented for the mouse heart, and data quality is improved using a data logger for additional gating and retrospective analysis.

\section{Background}

Myocardial perfusion is an indicator of cardiac health and an important parameter in detection and follow-up of cardiac disease. Myocardial perfusion can be measured in the mouse non-invasively with MRI using ASL (eg. [1], [2]).

\section{Methods}

Perfusion maps are generated by pixel-wise comparison of $\mathrm{T}_{1}$ maps from slice-selective and global inversion recoveries. $\mathrm{T}_{1}$ was quantified using ECG-gated LookLocker approach [3], with 4 lines of $\mathrm{k}$-space acquired every heartbeat to speed up acquisition by approximately four times compared with previous approaches (eg. [2],[3]).

A data logger (CED) was used to record ECG, RF and respiration events and was programmed to gate on each ECG peak detected as well as to interpolate peaks missed by physiological monitoring software. Using the information recorded, lines of $\mathrm{k}$-space were binned as 'acquired during respiration' or not. Images with many lines or centre lines of k-space acquired during respiration were rejected.

ASL data were acquired on a 9.4T Varian system with $35 \mathrm{~mm}$-long volume RF coil (Rapid) ( $\mathrm{TE}=1.18 \mathrm{~ms}$, flip $=5^{\circ}$,

${ }^{1}$ Centre for Advanced Biomedical Imaging, University College London, London, UK

Full list of author information is available at the end of the article resolution $=200 \mu \mathrm{m}$, slice thickness $=1.5 \mathrm{~mm}$ ) and image analysis was performed in Matlab.

\section{Results}

It was found that an average of 2 ECG peaks per inversion recovery were missed by the physiological monitoring software, compared to none using the data logger script. The percentage of $k$-space lines acquired during respiration for images in an inversion recovery is displayed in Figure 1. The pattern of Figure 1 is generated by the de-phasing of respiration and acquisition with changing respiration rate. This manifests as blurring to the final images of the inversion recovery curve.

Figure 2 presents an example ASL data set. The mean perfusion in the myocardium is estimated to be 7.0 $\pm 3.3 \mathrm{ml} / \mathrm{g} / \mathrm{min}$, which is consistent with literature values. Anatomical image quality is not compromised using this segmented $k$-space method and $T_{1}$ maps appear to have less respiration corruption.

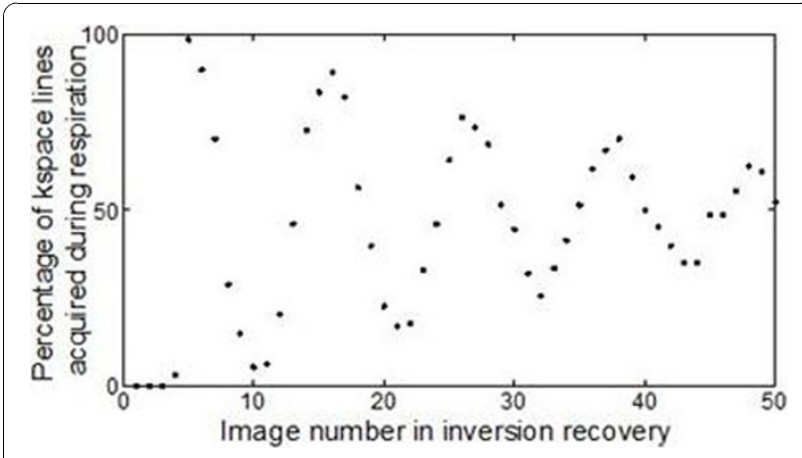

Figure 1 Percentage of k-space lines (for 128×128 matrix) which are acquired during respiration throughout inversion recovery.
C Biomed Central

() 2011 Campbell et al; licensee BioMed Central Ltd. This is an open access article distributed under the terms of the Creative Commons Attribution License (http://creativecommons.org/licenses/by/2.0), which permits unrestricted use, distribution, and reproduction in any medium, provided the original work is properly cited. 

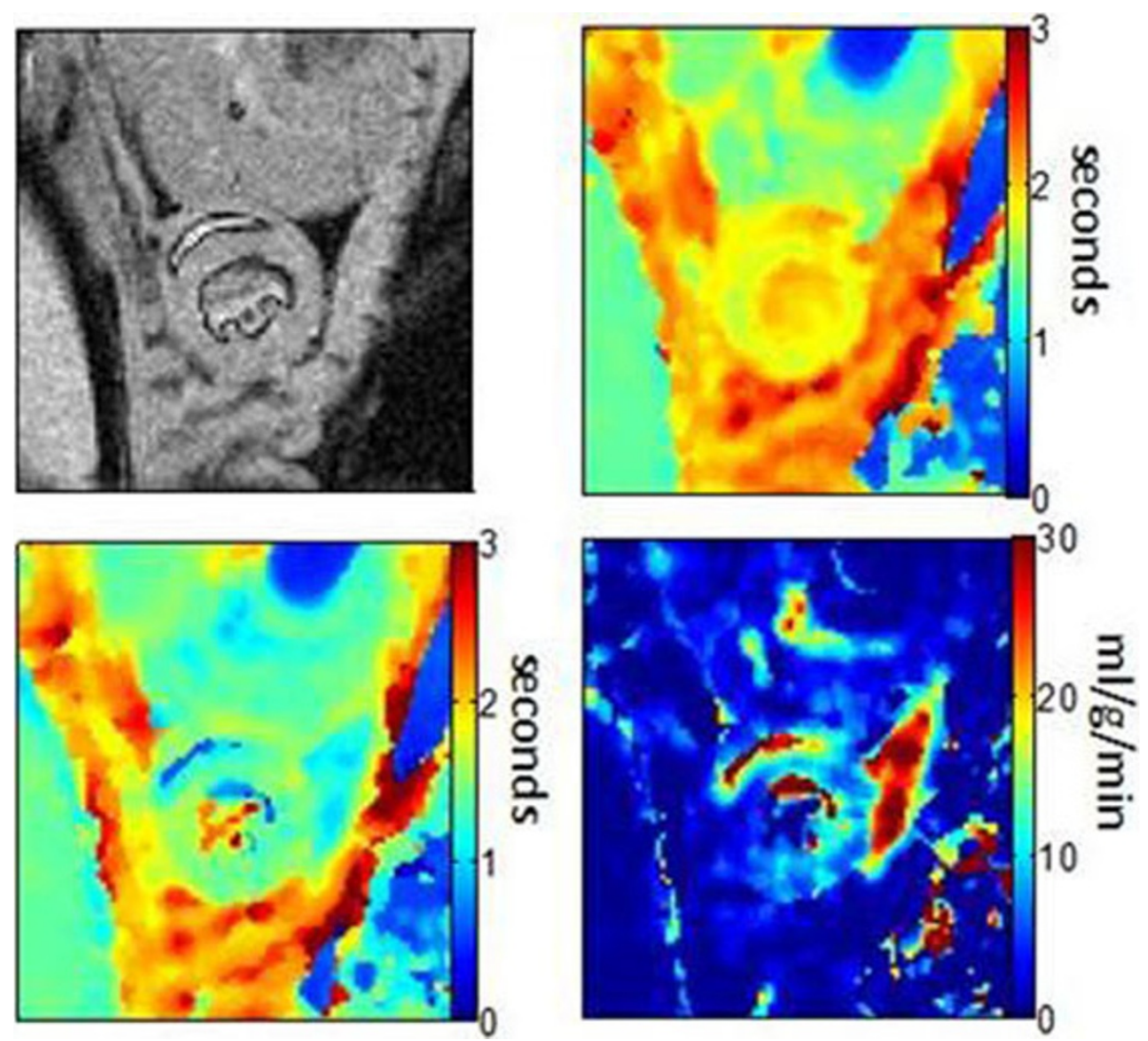

Figure 2 Example ASL data set from one mouse (heart rate $=550 \mathrm{bpm}$ ). a) Anatomical image, $\mathrm{T} 1 \mathrm{map}$ from b) global inversion recovery and c) slice-selective inversion recovery, and d) resulting perfusion map, with values greater than $30 \mathrm{ml} / \mathrm{g} / \mathrm{min}$ clipped.

\section{Conclusions}

This study presents a time-efficient acquisition of cardiac ASL data in the mouse, with improved data quality using a data logger to eliminate missed ECG triggers and to introduce objective criteria for rejection of respiration-corrupted images.

\section{Acknowledgement}

Thanks to Steven Clifford - CED data logger programming

\section{Author details}

${ }^{1}$ Centre for Advanced Biomedical Imaging, University College London, London, UK. ${ }^{2}$ Robert Steiner MRI Unit, Imperial College London, London, UK. ${ }^{3}$ Department of Medical Physics and Bioengineering, University College London, London, UK.

Published: 2 February 2011

\section{References}

1. Streif, et al: A. MRM 2005, 53:584-592.

2. Vandsburger, et al: MRM 2010, 63:648-657.

3. Kober, et al: MRM 2004, 51:62-67.

doi:10.1186/1532-429X-13-S1-P56

Cite this article as: Campbell et al:: Improved cardiac arterial spin labelling in the mouse heart by optimisation of acquisition and analysis. Journal of Cardiovascular Magnetic Resonance 2011 13(Suppl 1): P56.

\section{Submit your next manuscript to BioMed Central} and take full advantage of:

- Convenient online submission

- Thorough peer review

- No space constraints or color figure charges

- Immediate publication on acceptance

- Inclusion in PubMed, CAS, Scopus and Google Scholar

- Research which is freely available for redistribution 